\title{
Health-related quality of life in patients waiting for major joint replacement. A comparison between patients and population controls
}

\author{
Johanna Hirvonen*1,2, Marja Blom ${ }^{1,3,4}$, Ulla Tuominen ${ }^{1,2}$, Seppo Seitsalo ${ }^{5}$, \\ Matti Lehto ${ }^{6}$, Pekka Paavolainen ${ }^{5,7}$, Kalevi Hietaniemi ${ }^{4}$, Pekka Rissanen ${ }^{8}$ and \\ Harri Sintonen ${ }^{2}$
}

Address: ${ }^{1}$ National Research and Development Centre for Welfare and Health, Helsinki, Finland, ${ }^{2}$ University of Helsinki, Finland, ${ }^{3}$ Academy of Finland, ${ }^{4} \mathrm{HUCH}$, Jorvi Hospital, Espoo, Finland, ${ }^{5}$ Orton Orthopaedic Hospital, Helsinki, Finland, ${ }^{6} \mathrm{Coxa}$, Hospital for Joint Replacement, Medical Research Fund of Tampere University Hospital, Finland, ${ }^{7} \mathrm{HUCH}$, Surgical Hospital, Helsinki, Finland and ${ }^{8}$ University of Tampere, Finland

Email: Johanna Hirvonen* - johanna.hirvonen@stakes.fi; Marja Blom - marja.blom@stakes.fi; Ulla Tuominen - ulla.tuominen@stakes.fi; Seppo Seitsalo - seppo.seitsalo@invalidisaatio.fi; Matti Lehto - matti.lehto@coxa.fi; Pekka Paavolainen - pekka.paavolainen@invalidisaatio.fi; Kalevi Hietaniemi - kalevi.hietaniemi@hus.fi; Pekka Rissanen - pekka.rissanen@uta.fi; Harri Sintonen - harri.sintonen@helsinki.fi

* Corresponding author

Published: 19 January 2006

Health and Quality of Life Outcomes 2006, 4:3 doi:10.1 I86/1477-7525-4-3

This article is available from: http://www.hqlo.com/content/4/I/3

(c) 2006 Hirvonen et al; licensee BioMed Central Ltd.

This is an Open Access article distributed under the terms of the Creative Commons Attribution License (http://creativecommons.org/licenses/by/2.0), which permits unrestricted use, distribution, and reproduction in any medium, provided the original work is properly cited.
Received: 23 November 2005

Accepted: 19 January 2006

\begin{abstract}
Background: Several quality-of-life studies in patients awaiting major joint replacement have focused on the outcomes of surgery. Interest in examining patients on the elective waiting list has increased since the beginning of 2000. We assessed health-related quality of life (HRQoL) in patients waiting for total hip (THR) or knee (TKR) replacement in three Finnish hospitals, and compared patients' HRQoL with that of population controls.

Methods: A total of I 33 patients awaiting major joint replacement due to osteoarthritis (OA) of the hip or knee joint were prospectively followed from the time the patient was placed on the waiting list to hospital admission. A sample of controls matched by age, gender, housing and home municipality was drawn from the computerised population register. HRQoL was measured by the generic I5D instrument. Differences between patients and the population controls were tested by the independent samples t-test and between the measurement points by the paired samples t-test. A linear regression model was used to explain the variance in the I5D score at admission.

Results: At baseline, I5D scores were significantly different between patients and the population controls. Compared with the population controls, patients were worse off on the dimensions of moving $(P<0.00 I)$, sleeping $(P<0.00 I)$, sexual activity $(P<0.00 I)$, vitality $(P<0.00 I)$, usual activities $(P<0.00 I)$ and discomfort and symptoms $(P<0.00 I)$. Further, psychological factors - depression $(P<0.00 I)$ and distress $(P=0.004)-$ were worse among patients than population controls. The patients showed statistically significantly improved average scores at admission on the dimensions of moving $(P=0.026)$, sleeping $(P=0.004)$ and discomfort and symptoms $(P=0.04 I)$, but not in the overall I5D score compared with the baseline. In patients, I5D score at baseline $(P<$ $0.00 \mathrm{I})$ and body mass index $(\mathrm{BMI})(P=0.020)$ had an independent effect on patients' I5D score at hospital admission.
\end{abstract}

Conclusion: Although patients' HRQoL did not deteriorate while waiting, a consistently worse HRQoL was observed in patients waiting for major joint replacement compared with population controls. 


\section{Background}

The OECD Waiting Times project [1] on waiting time variations for elective surgery across OECD country showed waiting times to be "a significant health policy concern" in almost half of all OECD countries. Finland and the United Kingdom were the countries with the highest waiting times.

In Finland, major joint replacements are surgical procedures with high volume and relatively long waiting times. In 2003, almost 8800 hip replacement patients (169 per 100 000) and 6800 knee replacement patients (131 per 100 000) were operated in Finnish hospitalss [2]. Between 1987 and 2002, the THR rate rose on average by 5\% annually and the TKR rate by $12 \%$ [3]. Comparing waiting times among Finnish THR and TKR patients shows significant regional differences and a trend towards longer waiting times within the last ten years. In 2003, for patients with primary THR, the median waiting time was 155 days, and for patients with TKR 205 days [2].

To ensure the availability of care in Finland, the Council of State initiated in 2001 a national project to secure the future of health care. Guidelines for the implementation of a nationwide system for assessing health care needs and for the treatment criteria were prepared by the end of 2003. The national principles of access to hospital treatment within six months or less came into force in March 2005.

Several studies have assessed health-related quality of life (HRQoL) among patients who have undergone major joint replacement and shown that patients experience substantially more pain and restrictions in physical function than the general population [4-6]. Still, relatively few of them have examined the change in HRQoL that occurs while waiting for surgery. Studies have mostly focused on the outcomes of surgery, reported improvements in physical function, vitality and mental health and reductions in pain, or have shown that total knee arthroplasty (TKA) and total hip arthroplasty (THA) are beneficial and effective [7-13]. However, the interest in examining the relationship between HRQoL and time spent waiting for surgery has been on the increase since the beginning of 2000. The results have shown no consistent evidence that HRQoL is worse in patients having to wait longer [14-16]. However, a prospective Canadian study concluded that patients who wait 6 months at the most realize greater gains in HRQoL than those waiting longer [17]. Further, a prospective study of patients waiting for total hip arthroplasty (THA) found that patients in a later phase of disease did not reach the same level after THA as those with better preoperative function [4].
Although the principle of equal access to surgeries and other health services has been promoted by health policy in many western health care systems, practices do not totally equate to policy targets. A common view is that delayed access to care may impose a variety of costs such as welfare losses during the waiting period [18]. Still, evidence of the effect of waiting on patients' health status is mixed.

The purpose of this study is to assess HRQoL in patients awaiting major joint replacement and to compare the HRQoL of patients with that of population controls. The data collected for this analysis is part of long-term followup data for patients in a prospective multi-centre study aimed at assessing the costs and effects of waiting.

\section{Methods \\ Data collecting}

Patients were enrolled into this study in three Finnish hospitals (HUCH Surgical Hospital, Helsinki; HUCH Jorvi Hospital, Espoo and Coxa Hospital for Joint Replacement, Tampere) in two hospital districts (Hospital District of Helsinki and Uusimaa and Pirkanmaa Hospital District). Two hospitals provide surgical services for municipalities in the capital area. The third hospital is specialised in endoprosthetic surgery which provides services for municipalities, local and central hospitals, as well as for patients paying the costs themselves.

Patients were recruited into the study through regular contact with the orthopaedic surgeons and practice staff. The Ad hoc recruitment began in August 2002 and finished in November 2003.

The inclusion criteria were: need for a primary total joint arthroplasty due to osteoarthritis (OA) of the hip or knee joint (excluding rheumatoid arthritis, fractures, haemophilia and deformity) as evaluated by the hospital surgeon, a patient aged 16 years or older was placed on the waiting list in a research hospital, and the patient was willing and mentally able to participate in the study. Each patient provided a signed informed consent. The study had ethical approval from the Helsinki University Central Hospital (HUCH) Surgery Ethics Committee.

Patients completed a self-administered questionnaire at two specific points in time: 1) when placed on the waiting list (baseline), and 2) at hospital admission. The questionnaires were distributed to patients at hospital. Return of the questionnaires was via postal means. Common guidelines for administering the questionnaires were provided at each hospital.

For each patient, two population controls matched by age, gender, housing (living alone vs. living with someone) 
Table I: Characteristics of patients and population controls

\begin{tabular}{|c|c|c|c|c|c|}
\hline Characteristic & $\begin{array}{l}\text { Patients } \\
n=133\end{array}$ & $\begin{array}{c}\text { Population controls } \\
n=129-133^{b}\end{array}$ & $\begin{array}{c}\text { Patients excluded } \\
n=61-64^{b}\end{array}$ & P value & P value $^{d}$ \\
\hline Age, years (mean $\pm S D)$ & $67.6(8.8)$ & $67.6(8.8)$ & $66.0(13.2)$ & 1.000 & 0.375 \\
\hline Females $[\mathrm{n},(\%)]$ & $83(62.4)$ & $81(60.9)$ & $43(67.2)$ & 0.801 & 0.513 \\
\hline Home municipality [n, (\%)] & & & & 0.900 & 0.534 \\
\hline Capital area & $72(54.1)$ & $71(53.4)$ & $38(59.4)$ & & \\
\hline Other urban area & $36(27.1)$ & $39(29.3)$ & $18(28.1)$ & & \\
\hline Rural area & $25(18.8)$ & $23(17.3)$ & $8(12.5)$ & & \\
\hline Housing, living alone $[\mathrm{n},(\%)]$ & $39(29.3)$ & $40(30.3)$ & $29(47.5)$ & 0.862 & 0.014 \\
\hline Professional examination, yes $[\mathrm{n},(\%)]$ & $45(33.8)$ & $61(47.3)$ & $23(37.7)$ & 0.027 & 0.600 \\
\hline Employment status [n, (\%)] & & & & 0.229 & 0.066 \\
\hline Employed & $17(12.8)$ & $27(20.3)$ & $16(26.2)$ & & \\
\hline Retired & $112(84.2)$ & $101(75.9)$ & $43(70.5)$ & & \\
\hline Other & $4(3.0)$ & $5(3.8)$ & $2(3.3)$ & & \\
\hline Comorbidity, yes [n, (\%)] & $89(66.9)$ & $98(73.7)$ & $48(78.7)$ & 0.227 & 0.095 \\
\hline $\mathrm{BM} \mathrm{I}^{\mathrm{a}}($ mean $\pm \mathrm{SD})$ & $29.0(4.4)$ & $26.8(4.4)$ & $28.3(4.7)$ & $<0.001$ & 0.280 \\
\hline Waiting time, days [Md, range] & $71(8-600)$ & & & & \\
\hline \multicolumn{6}{|l|}{ Months waiting for surgery [n, (\%)] } \\
\hline $0-3$ months & $94(70.7)$ & & & & \\
\hline$>3-6$ months & $20(15.0)$ & & & & \\
\hline$>6$ months & $19(14.3)$ & & & & \\
\hline
\end{tabular}

a BMI, body mass index (wt/ht $\left.{ }^{2}\right)$

b Number of observations varies due to missing values.

c Between patients and population controls

d Between the patients who completed the questionnaires (baseline and admission, $n=133$ ) and those excluded $(n=64)$

and home municipality were obtained from the National Population Register of Finland. To minimise the loss of participants, two controls per patient were selected. Thus control subject who did not return the questionnaire was replaced with the other control of the same patient. In the autumn of 2003, controls were mailed a self-administered questionnaire similar to the patients' questionnaire.

\section{HRQoL instrument}

We assessed HRQoL using 15D. The 15D is a generic and standardised HRQoL instrument consisting of 15 dimensions: moving, seeing, hearing, breathing, sleeping, eating, speech, elimination, usual activities, mental function, discomfort and symptoms, depression, distress, vitality and sexual activity. For each dimension, the respondent must choose one of the five levels that best describes his/ her state of health at the moment (best level $=1$; worst level = 5) $[19,20]$. The single index (15D score) on a $0-1$ scale, representing the overall HRQoL, is calculated from the health state descriptive system by using a set of population-based preference or utility weights. Such a weight for each level of each dimension is obtained by multiplying the level value by the importance weight of the dimension at that level [21]. The level values on a $0-1$ scale, reflecting the goodness of the levels relative to no problems on the dimension $(=1)$ and to being dead $(=0)$, and the importance weights summing up to unity, have been elicited from representative population samples. The 15D has been/is being utilised among different patient groups (e.g. patients undergoing hip or knee arthroplasty) to assess outcomes from health care interventions $[13,20,22]$. In most of the important properties (eg. responsiveness, sensitivity, reliability and validity), the 15D compares favourably with other instruments of the same kind, such as EQ-5D, HUI3, SF-6D and AQoL [20,21,23-25].

The interpretation on the minimum clinically important difference in the $15 \mathrm{D}$ score is a difference \pm 0.03 or more (on a scale 0-1) in the sense that people can feel the difference in health status [26].

\section{Statistical analysis}

Data were analysed using SPSS for Windows, version 12.0.1. Descriptive statistics were used to describe demographic characteristics. Comparative analyses of demographic characteristics between patients and population controls were computed using either the independent samples t-test or the Chi-squared test depending on the levels of measurement.

Univariate analyses were conducted to determine a) the differences in the 15D score and dimensions between patients and population controls, and b) the differences between the baseline and admission measurements within the patient group. Mean group scores were compared using the paired samples t-test test within the patient group, and independent samples t-test between 
Table 2: The average I5D scores and dimension level values between patients and population controls

\begin{tabular}{|c|c|c|c|}
\hline Health outcome & Patients & Population controls & Mean difference ${ }^{b}(95 \% \mathrm{Cl})$ \\
\hline \multicolumn{4}{|l|}{ I5D dimension ${ }^{\mathrm{a}}$} \\
\hline Moving & $0.565(0.127)$ & $0.883(0.172)$ & $0.317 * * * *(0.281,0.354)$ \\
\hline Seeing & $0.909(0.176)$ & $0.943(0.140)$ & $0.034 n s(-0.004,0.073)$ \\
\hline Hearing & $0.914(0.142)$ & $0.941(0.143)$ & $0.027 n s(-0.007,0.062)$ \\
\hline Breathing & $0.866(0.204)$ & $0.867(0.219)$ & 0.00 Ins $(-0.050,0.052)$ \\
\hline Sleeping & $0.685(0.224)$ & $0.803(0.186)$ & $0.117 * * *(0.068,0.167)$ \\
\hline Eating & $0.992(0.053)$ & $0.992(0.053)$ & 0.000 ns $(-0.013,0.013)$ \\
\hline Speech & $0.989(0.057)$ & $0.978(0.079)$ & -0.01 Ins $(-0.028,0.005)$ \\
\hline Elimination & $0.848(0.202)$ & $0.876(0.193)$ & $0.028 \mathrm{~ns}(-0.020,0.076)$ \\
\hline Usual activities & $0.655(0.217)$ & $0.870(0.199)$ & $0.214 * * *(0.164,0.264)$ \\
\hline Mental function & $0.864(0.178)$ & $0.897(0.170)$ & $0.033 n s(-0.009,0.075)$ \\
\hline Discomfort and symptoms & $0.473(0.236)$ & $0.784(0.204)$ & 0.311 I*** $(0.258,0.364)$ \\
\hline Depression & $0.829(0.177)$ & $0.902(0.138)$ & $0.074 * * *(0.035,0.112)$ \\
\hline Distress & $0.831(0.188)$ & $0.892(0.155)$ & $0.06 I^{* *}(0.019,0.102)$ \\
\hline Vitality & $0.748(0.172)$ & $0.852(0.152)$ & $0.104 * * *(0.065,0.143)$ \\
\hline Sexual activity & $0.731(0.273)$ & $0.869(0.239)$ & $0.138 * * *(0.076,0.200)$ \\
\hline I5D score & $0.778(0.091)$ & $0.883(0.103)$ & $0.105^{* * *}(0.082,0.129)$ \\
\hline
\end{tabular}

$\mathrm{n}=133$

a Data are mean (SD) scores. The scale is $0-1$, worst to best.

$\mathrm{b}$ Baseline scores between patients and population controls. Positive difference indicates better score and negative difference indicates worse score for population controls than for patients. ns, non-significance

$* \mathrm{P}<0.05, * * \mathrm{P}<0.01$, *** $\mathrm{P}<0.001$

patients and population controls. Two-sided P-values were calculated in all tests. A P-value $<0.05$ was considered statistically significant.

A multiple linear regression (MLR) model on the patient data was constructed to determine the relationships between the independent variables (waiting time, BMI, affected joint, 15D score at baseline, gender, age, education, housing) and 15D score at admission. Waiting time was skewed and thus included in the model as a categorical variable (over 3-6 months, over 6 months and 0-3 months as a reference level). All available independent variables were included in the model. The results are presented in the form of unstandardised $\beta$-coefficients.

Missing values for the 15D dimensions were predicted with the responses on the other dimensions, age and gender as explanatory variables [19]. The missing value was substituted if a minimum $80 \%$ of dimensions were present.

\section{Results}

\section{Patient and population controls characteristics}

Of the 197 eligible patients recruited into the study, 30 were excluded because their controls declined to participate. In addition, 6 patients did not complete the baseline and 28 did not complete the admission questionnaire and were excluded. The analysis presented here focuses on 133 pairs with completed questionnaires.
The average age of the study population including patients and age matched population controls was 67.6 years (range, 36-86 years) (Table 1). Of patients, 73 $(55 \%)$ were waiting for primary THR and $60(45 \%)$ were waiting for primary TKR. The majority $(54 \%, n=143)$ of the participants (including patients and population controls) were from capital area. A total of $75(28 \%)$ participants were from other urban area and $48(18 \%)$ from rural area.

A comparison between patients and population controls showed that controls had more often professional education than patients and patients were heavier than controls. Of patients, $21(16 \%)$ had a normal BMI $(<25)$ and 112 $(84 \%)$ were overweight or obese (BMI $\geq 25)$. Of population controls, 45 (34\%) had a normal BMI, and 86 (66\%) were overweight or obese.

For the patients, the waiting time from the surgeon appointment to the surgery was skewed such that a total of $94(71 \%)$ patients waited for surgery $0-3$ months, 20 (15\%) waited > 3-6 months and 19 (14\%) waited over 6 months. Two patients waited over one year.

A comparison between patients who completed the questionnaires (baseline and admission) and those who were excluded showed that those who were excluded were more often living alone than the completers $\left(\mathrm{X}^{2}=6.1, \mathrm{P}=\right.$ 0.014 ). There was, however, no statistically significant or clinically important difference in the baseline 15D score 
Table 3: Multiple linear regression coefficient estimates for the patients' I5D score at admission

\begin{tabular}{|c|c|c|c|}
\hline Explanatory variables & $\beta^{a}$ & $95 \% \mathrm{Cl}$ for $\beta$ & $P$ value \\
\hline \multicolumn{4}{|l|}{ Waiting time } \\
\hline $0-3$ months & Reference & & \\
\hline$>3-6$ months & 0.013 & $-0.016,0.043$ & 0.381 \\
\hline$>6$ months & 0.017 & $-0.014,0.047$ & 0.286 \\
\hline BMI & -0.003 & $-0.005,-0.0004$ & 0.020 \\
\hline Affected joint $(0=$ hip, $\mathrm{I}=$ knee $)$ & 0.013 & $-0.009,0.035$ & 0.232 \\
\hline I5D score at baseline & 0.752 & $0.637,0.867$ & $<0.001$ \\
\hline Gender $(0=$ female, $I=$ male $)$ & -0.008 & $-0.032,0.015$ & 0.479 \\
\hline Age & -0.0004 & $-0.002,0.001$ & 0.539 \\
\hline Professional education $(0=$ no, $\mathrm{I}=$ yes $)$ & -0.0003 & $-0.023,0.022$ & 0.976 \\
\hline Housing ( 0 = living alone, $I=$ living with someone) & 0.009 & $-0.016,0.034$ & 0.469 \\
\hline Constant & 0.301 & & \\
\hline$R$ square & 0.613 & & \\
\hline $\mathrm{F}$ & $21.430 * * * *$ & & \\
\hline$n$ & 133 & & \\
\hline
\end{tabular}

A positive value indicates improvement in the I5D score, and a negative value indicates worsening. a multivariate unstandardised linear regression coefficient $* * * \mathrm{P}<0.001$

between the completers and those excluded $(0.778$ and 0.777 , respectively; $\Delta 0.001, \mathrm{t}=0.03, \mathrm{P}=0.980$ ).

\section{HRQoL among patients and population controls}

At the time the patients were placed on the waiting list, the average (SD) 15D score was 0.778 (0.091) (Table 2). Among the population controls, the mean (SD) 15D score was $0.883(0.103)$. The difference was statistically significant and clinically important. The difference between the groups remained statistically significant and clinically important when patients' HRQoL at admission was compared with the HRQoL among the population controls. At baseline, patients had statistically significantly lower scores on the dimensions of moving, sleeping, usual activities, discomfort and symptoms, depression, distress, vitality and sexual activity compared to population controls.

\section{Change in patients' HRQoL while waiting}

In patients, the 15D score improved while waiting, but the change was not statistically significant or clinically important $(\Delta 0.008, \mathrm{t}=1.6, \mathrm{P}=0.123,95 \%$ confidence interval, CI: 0.002-0.019). The patients showed, however, statistically significantly improved average scores at admission for moving $(\Delta 0.032, \mathrm{t}=2.2, \mathrm{P}=0.026,95 \%$ CI: $0.004-$ $0.060)$, sleeping $(\Delta 0.042, \mathrm{t}=3.0, \mathrm{P}=0.004,95 \% \mathrm{CI}$ : $0.014-0.071)$ and discomfort and symptoms $(\Delta 0.038, \mathrm{t}=$ 2.1, $\mathrm{P}=0.041,95 \% \mathrm{CI}: 0.002-0.075)$ compared with the baseline measurement (not shown).

\section{Patients' HRQoL at admission}

The results of the MLR analysis indicated that BMI $(\beta=-$ $0.003, P=0.020)$ and the $15 \mathrm{D}$ score at baseline $(\beta=$
$0.752, \mathrm{P}<0.001)$ were significantly associated with the $15 \mathrm{D}$ at admission (Table 3). A higher BMI when placed on the waiting list was associated with the worse $15 \mathrm{D}$ score at admission and the higher 15D score at baseline was associated with higher HRQoL at admission. The length of waiting was unrelated to the $15 \mathrm{D}$ score at admission.

\section{Discussion}

The aim of this multi-centre study was to assess HRQoL in patients awaiting major joint replacement and to compare the HRQoL of patients with that of population controls. Patients were recruited into the study in three large Finnish hospitals across two hospital districts and were prospectively followed from the time the patient was placed on the waiting list to the time of admission, with waiting times calculated exactly. HRQoL was measured by the $15 \mathrm{D}$, which is a generic, standardised, self-administered measure and has been utilised in clinical economic evaluations and population studies [20].

Some previous studies have reported that those awaiting hip or knee replacement have a significantly poorer quality of life - especially in physical and social life - than a general population $[5,27]$. The results of this study are in line with those studies. Our first main finding was that at both measurement points, patients awaiting major joint replacement suffered from a significantly poorer HRQOL - especially in moving, sleeping, usual activities, discomfort and symptoms, depression, distress, vitality and sexual activity - compared to the population controls. However, mental function seemed unaffected by the disease. This finding seems to be in line with an English casecontrol study of patients awaiting hip replacement for 
osteoarthritis [5], but in contrast to a recent Australian study by Ackerman et al. [28] who found that patients waiting for joint replacement suffered significantly higher psychological distress compared with the general population.

Our second main finding was that patients' overall HRQoL improved while waiting although the improvement was not statistically significant or clinically important. The patients showed, however, statistically significantly improved average scores at admission for moving, sleeping and discomfort and symptoms compared with the time when placed on the waiting list. This is somewhat paradoxical and may reflect patients' expectations on the coming surgical intervention that is supposed to relief the disabling symptoms and to improve function.

Multivariate analysis found that baseline HRQoL and BMI were associated with HRQoL at admission. An increased BMI was associated with a poorer HRQoL and better HRQoL at the time of listing for surgery predicted a better HRQoL at admission. We found, however, no association between the length of waiting time and HRQoL at admission. This result is partially in line with the studies [14$17,27]$ that have found no significant differences in HRQoL between patients with short waits and those with longer waits. The explanations are various and should be analysed in more detail. For example, it might be possible that after making a decision to operate, the certainty of treatment has a positive impact on health status. Nilsdotter et al. [15] have talked about "regression to the mean", in that with the decision, the health status may even improve. In addition, Achat et al. [29] have found that optimism in older patients is associated with better general health perception. Although patients' HRQoL did not seem to decrease while waiting and no association between waiting time and poorer HRQoL at admission was found, this does not, however, affect our general conclusion that patients awaiting major joint replacement due to OA suffer from discomfort and symptoms, and have a clear reduction in moving, usual activities, sleeping, energy, sexual life and some mental aspects (distress, depression). Although further deterioration in HRQoL may be limited after placement on the waiting list, delayed access to surgery impose the burden of disease.

There were some limitations in our study. First, most patients were residing in the urban area, which may limit our study's generalizability to rural populations. A previous study has shown that urban THR patients may differ from rural patients with respect to pain threshold and perceptions on function [30]. Second, the median length of waiting time among patients was rather short (72 days) and thus the sample may have under-represented those having to wait longer and resulted in an underestimation of the waiting time effect on HRQoL. As the median waiting times in Finland are longer, the study's finding should not necessarily be generalised to all patients awaiting THR or TKR. Further, we measured the time between placement on the waiting list and hospital admission instead of following patients from general practitioner's consultation to treatment. Ideally, the whole waiting time from initial referral to the specialist should be monitored [31]. In prospective studies, it is, however, difficult to collect waiting time data through the care process from primary care consultation to treatment. Third, the population controls had more often a professional education compared to the patients, which may have impacted on the findings as socioeconomic status (SES) has been shown to be associated with health status $[30,32]$.

\section{Conclusion}

In these analyses, we found that the length of waiting was unrelated to the poorer HRQoL at admission. Further, moving, sleeping and discomfort and symptoms improved while waiting for surgery. An interesting view concerning these dimensions is that we do not know the association of disease specific medication with HRQOL and reduction in pain during the waiting time. Although patients' HRQoL measured by the generic 15D instrument improved minimally while waiting, a consistently worse HRQoL was observed in patients waiting for major joint replacement compared with population controls. Thus, it is essential to identify on the waiting list those in the poorest health.

\section{Competing interests}

The author(s) declare that they have no competing interests.

\section{Authors' contributions}

$\mathrm{JH}$ was the correspondence author of the manuscript and responsible for the integrity of the work as a whole. She contributed as a principal researcher and writer including drafting the article and the analysis and interpretation of data. MB was the leader of the research project. She made contributions to conception and design, acquisition and interpretation of data and participated in the writing process by commenting the manuscript. UT made contributions to design, acquisition, and interpretation of data. HS and PR contributed as specialists in the field, were involved in the design of the study and hypothesis formation and revised the manuscript. SS, ML, PP, KH contributed as specialists in the field of orthopaedic surgery. They made contributions to design and acquisition of data and revised the manuscript. All authors read and approved the final manuscript.

\section{Acknowledgements}


This study was financially supported by the Academy of Finland (no. 5187I), Helsinki University Central Hospital Jorvi Hospital, Coxa Hospital for Joint Replacement, Medical Research Fund of Tampere University Hospital, Helsinki University Central Hospital Surgical Hospital and Orton Orthopaedic Hospital.

\section{References}

I. Siciliani L, Hurst J: Explaining waiting times variations for elective surgery across OECD countries. OECD Health Working Papers 2003, 7:.

2. National Research and Development Centre for Welfare and Health. Operative inpatient services 2003 [http:// www.stakes.info/2/9/hoitojaksot 2003.asp]

3. Mikkola H, Järvelin J, Seitsalo S, Keskimäki I: Orthopedic surgeries in Finland 1987-2002. Number of surgeries according to the geographic areas, waiting time and centralization. Duodecim 2005, I 2 I:86 I-87|.

4. Ostendorf M, Buskens E, van Stel H, Schrijvers A, Marting L, Dhert W, Verbout A: Waiting for Total Hip Arthroplasty. Avoidable Loss in Quality Time and Preventable Deterioration. J Arthroplasty 2004, 19:302-309.

5. Croft P, Lewis M, Wynn Jones C, Coggon D, Cooper C: Health status in patients awaiting hip replacement for osteoarthritis. Rheumatology (Oxford) 2002, 9:1001-1007.

6. Jones CA, Voaklander DC, Johnston DW, Suarez-Almazor ME: Health related quality of life outcomes after total hip and knee arthroplasties in a community based population. J Rheumatol 2000, 27: I745-I752.

7. Bachmeier CJ, March LM, Cross MJ, Lapsley HM, Tribe KL, Courtenay BG, Brooks PM, Arthritis Cost and Outcome Project Group: A comparison of outcomes in osteoarthritis patients undergoing total hip and knee replacement surgery. Osteoarthritis Cartilage 2001, 2:137-146.

8. Chiu HC, Mau LW, Hsu YC, Chang JK: Postoperative 6-month and I-year evaluation of health-related quality of life in tota hip replacement patients. J Formos Med Assoc 200I, 7:46I-465.

9. Brander VA, Malhotra S, Jet J, Heinemann AW, Stulberg SD: Outcome of hip and knee arthroplasty in persons aged 80 years and older. Clin Orthop 1997, 345:67-78.

10. March LM, Cross MJ, Lapsley H, Brnabic AJM, Tribe KL, Bachmeier CJM, Courtenay BG, Brooks PM: Outcomes after hip or knee replacement surgery for osteoarthritis. A prospective cohort study comparing patients' quality of life before and after surgery with age-related population norms. MJA 1999, I 7 |:235-238.

II. McGuigan FX, Hozack WJ, Moriarty L, Eng K, Rothman RH: Predicting quality-of-life outcomes following total joint arthroplasty. Limitations of the SF-36 Health Status Questionnaire. J Arthroplasty 1995, 6:742-747.

12. Salmon P, Hall GM, Peerbhoy D, Shenkin A, Parker C: Recovery from hip and knee arthroplasty: Patients' perspective on pain, function, quality of life, and well-being up to 6 months postoperatively. Arch Phys Med Rehabil 200I, 3:360-366.

13. Rissanen P, Aro S, Sintonen H, Slatis P, Paavolainen P: Quality of life and functional ability in hip and knee replacements: a prospective study. Qual Life Res 1996, I:56-64.

14. Brownlow HC, Benjamin S, Andrew JG, Kay P: Disability and mental health of patients waiting for total hip replacement. Ann $R$ Coll Surg Engl 200I, 2: I 28-133.

15. Nilsdotter AK, Lohmander LS: Age and waiting time as predictors of outcome after total hip replacement for osteoarthritis. Rheumatology 2002, 41:1261-1267.

16. Kelly KD, Voaklander DC, Johnston DWC, Newman SC, SuarezAlmazor ME: Change in pain and function while waiting for major joint arthroplasty. J Arthroplasty 200I, 3:35I-359.

17. Mahon JL, Bourne RB, Rorabeck CH, Feeny DH, Stitt L, WebsterBogaert S: Health-related quality of life and mobility of patients awaiting elective total hip arthroplasty: a prospective study. CMAI 2002, I0: I II5-1I21

18. Martin S, Smith PC: Rationing by waiting lists: an empirical investigation. J Public Econ 1999, 71:141-164.

19. Sintonen $\mathrm{H}$ : The I5D measure of health-related quality of life: reliability, validity and sensitivity of its health state descriptive system. In Working Paper 4 I NCHPE: Australia, Melbourne; 1994.
20. Sintonen $\mathrm{H}$ : The I5D instrument of health-related quality of life: properties and applications. Ann Med 200I, 33:328-336.

21. Sintonen H: The I5-D Measure of Health Related Quality of Life. II Feasibility and Validity of its Valuation System. In National Centre for Health Program Evaluation, Working Paper 42 Australia, Melbourne; 1995.

22. Rissanen $\mathrm{P}$, Aro S, Slätis $\mathrm{P}$, Sintonen H, Paavolainen P: Health and quality of life before and after hip or knee arthroplasty. J Arthroplasty 1995, 10:169-175.

23. Stavem K: Reliability, validity and responsiveness of two multiattribute utility measures in patients with chronic obstructive pulmonary disease. Qual Life Res 1999, 8:45-54.

24. Hawthorne G, Richardson J, Day NA: A comparison of the Assessment of Quality of Life (AQoL) with four other generic utility instruments. Ann Med 200I, 33:358-370.

25. Sintonen H: Properties of the health state descriptive system. [http://www. I5d-instrument.net/service.cntum?pageld=1 I0290].

26. Drummond $M$ : Introducing economic and quality of life measurements into clinical studies. Ann Med 200I, 5:344-349.

27. Derrett S, Paul C, Morris JM: Waiting for elective surgery: effects on health-related quality of life. Int J Qual Health Care 1999, I:47-57.

28. Ackerman IN, Graves SE, Wicks IP, Bennell KL, Osborne RH: Severely Compromised Quality of Life in Women and Those of Lower Socioeconomic Status Waiting for Joint Replacement Surgery. Arthritis Rheum 2005, 53:653-658.

29. Achat H, Kawachi I, Spiro A 3, DeMolles DA, Sparrow D: Optimism and depression as predictors of physical and mental health functioning: the Normative Aging Study. Ann Behav Med 2000, 22: $127-130$.

30. Visuri T, Honkanen R: The role of socio-economic status and place of residence in total hip replacement. Scand J Soc Med 1982, 10:95-99.

31. Standing Committee of the Hospitals of the E.U: Waiting lists and waiting times in health care. Managing demand and supply. Leuven $200 \mathrm{I}$.

32. Hawker GA, Wright JG, Glazier RH, Coyte PC, Harvey B, Williams JI, Badley EM: The Effect of Education and Income on Need and Willingness to Undergo Total Joint Arthroplasty. Arthritis Rheum 2002, 46:3331-3339.

Publish with Biomed Central and every scientist can read your work free of charge

"BioMed Central will be the most significant development for disseminating the results of biomedical research in our lifetime. "

Sir Paul Nurse, Cancer Research UK

Your research papers will be:

- available free of charge to the entire biomedical community

- peer reviewed and published immediately upon acceptance

- cited in PubMed and archived on PubMed Central

- yours - you keep the copyright

Submit your manuscript here:

http://www.biomedcentral.com/info/publishing_adv.asp
BioMedcentral 